\title{
HOLDING PATTERNS: Sand and Political Time at China's Desert Shores
}

\author{
JERRY C. ZEE \\ University of California, Santa Cruz \\ (D) http://orcid.org/0000-0002-2731-2130
}

Ocean, don't be afraid.

The end of the road is so far ahead it is already behind us.

Li Ming, an ecologist, and forestry official Tian are standing with me in the footprint of Qingtu Lake. Once the anchor of a verdant oasis of reedy wetlands in Gansu Province's Minqin County, today the lake is an expanse of sand that extends past the horizon. As late as the 1950s, Qingtu Lake sprawled luxuriantly across four hundred square kilometers, sixty meters deep at its lowest point. In the span of decades, with its groundwater drained in the utopian social-agricultural experiments of high Maoist socialism, the lake disappeared completely, leaving a carpet of mobile, alkaline sand. It swirls around our heels like water lapping on a still-remembered shore. It pools around our boots. On the spring day that Li, Tian, and I have come, we walk across the lakebed, wading shoulder-deep in absent water.

Minqin County is dotted with places like the lake, where the relentless pace of desertification has disjoined toponyms from the landscapes they named just decades before. ${ }^{1}$ Minqin, once an oasis en route to the eastern terminus of the Silk Road, is wedged at the sandy nexus of three provinces: Gansu, Inner Mon- 
golia, and Ningxia. It is today an archipelago of places scattered like islands in what many of the state foresters to whom I speak call the shahai, the sea of sand. The oceanic turn of phrase, sand-sea, is a metaphor that spotlights the possible meanings for sand and desert in Minqin. It draws attention not only to the sheer size of new and active desert lands but also to their oceanic activity. Loosed on the wind, desert sands gather into dunes that flow like a slow liquid, land swallowing land.

In this sand-sea, places like Minqin, facing the expanding sand, exist in the grim anticipatory state of the not-yet-buried. ${ }^{2}$ As two deserts run aground over the oasis, scientists scramble to devise methods for modeling dune drift in the region (Sun et al. 2005), generating scenarios that project Minqin's ultimate burial in the coming decades. For China's State Forestry Administration, the disappeared Qingtu Lake has become a powerful cautionary site in the central government's fight against desertification. Sand-control campaigns across China's desertification hot zones have become anxious stagings in the state's combat against mobile sands that now drift over a quarter of China's landmass and periodically rise into its skies as dust storms (Liu and Diamond 2005).

Today, exposed lakebed sands make the air a translucent haze that stings our eyes and scratches our throats. For the forestry official Tian, the lake is Minqin itself. From our vista point on the lakebed, Tian, who is in his fifties, recounts the waterfowl that have long stopped coming. He remembers taking his children swimming here. "The lake contracted, slowly and then quickly," he remembers. "Where it dried, the sand on its bed was free to move everywhere. With no water, the farms went dry. Even if they did not become sand, it was impossible to keep sand from burying the fields." In his telling, sand has become a mineral spur to remembering. It "holds geological memories in its elemental structure, and calls forth referential memories" (Agard-Jones 2012, 326). In its texture, color, and dryness on the skin, exposed sand opens a catalog of environmental changes and disappearances.

Sand renders time into recursions. Remembering through sand in this way also constitutes a foretelling. As a material that moves, accretes, holds momentarily steady, or tends to dissolution, it draws together past and future burialseach "an exception, shall we say, that announces itself only as an example" (Song 2012, 131). It not only provides an occasion for memory but also gives form to a way of thinking time in Minqin. Past burial events appear as an earthly momentum; sand's materiality is cautionary. "In ten years, twenty years, or five years, the sands will swallow Minqin, too,” Tian says, pushing his hands together 
to mimic the press of the two deserts that flank the sand-locked county. This pressing is a foretelling of Minqin's future from the perspective of a past ending, each of which becomes an example of sand's powers to bury. Sand, for the forestry official, offers a medium through which pasts and presents come to form. Its past and future motions link memory and prognostication as the repetitive realization of a process already imminent in the geodynamics of the unrestrainable desert. As lakebed sand slips through my fingers to trace out the direction of the breeze, Li Ming, my ecologist friend, explains, "In places like this, we are no longer confronted with the problem of development [fazhan], but rather with the question of existence [cunzai].”

In this article, I follow Tian, Li Ming, and their colleagues in learning to tell time through sand. In the various ways that sand itself shapes state landscape engineering, sand operates as what Stefan Helmreich $(2011,132)$ calls a "theory machine" at the interface of material processes, environmental change, and the chronological conditions and tactics of political intervention. Telling time through sand's properties is a way of giving form to a "near future" (Guyer 2007, 410) that forces environmental engineers and anthropologists to grapple with modes of reckoning time poised between the immediacy of omnipresent crisis (Massumi 2009) and long-term environmental collapse. I ask how sand-control programs in practice make governmental control of and intervention into time a site of chronopolitical experiment, where the soaring futures of the state are reshaped through sand as a material that variously accretes, buries, oscillates between motion and stability, or provides a habitat for geoengineering plants.

The question of the Anthropocene and contemporary environmental challenges demand ways of imagining the future in the obliteration of a cleavage between human and environmental history (Chakrabarty 2009). Whereas in many contemporary Anthropocene imaginaries, environment increasingly scripts an earthly future speeding toward disaster, in this article, I begin by noticing that earthly processes are increasingly reframed as a way of planetary fortune-telling. For instance, in tracing out contemporary environmental processes as the engine of a coming cataclysm, the dynamics of anthropogenic earth systems also become the template for a temporal form that arcs toward disaster. In what Naomi Oreskes and Erik Conway (2014), in their sci-fi history of the future, call the Great Collapse - the inevitable climatic-political resolution of today's Great Acceleration_climate projections are also narrative forms. In an increasing alignment of environmental processes with doomsday, environment, today, is increasingly the name of a powerful process that vibrates with the sense of an ending. But for 
sand-control engineers and ecologists, sand discloses futures that may also challenge the singular narratives of environmental ending, while in the meantime earthly and political rhythms demand new vocabularies for futures that end, but may also cycle, endure, and recur again.

Sand's multiple temporalities rework the chronopolitical stakes of environmental governance in various technical, personal, and scientific sites across desertifying China, while also signaling an expansive repertoire of intra-actions of environmental and political time. By chronopolitics, I mean the various ways in which the political does not merely operate in "empty, homogenous time" (Benjamin 1969, 261), but rather, tacitly and sometimes explicitly, makes the manipulation, acceleration, or projection of time both the condition and ongoing goal of political and governmental intervention. Through ethnographic research in the scientific, political, and engineering apparatus that aims to control desertification in China, I explore how state antidesertification programs confront sand and align political interventions with temporal formations that route politics through the dynamics of material, environmental, and ecological processes. A chronopolitics of earthly endurance, forestalled burial, and the kick-starting of ecological cycles begins from the encounter with sand's various temporalities. Engaging with sand as a material, narrative, and processual substrate of emergent temporal formations offers a method for thinking beyond what some accounts of the Anthropocene render as a geological stage hemming the future into a singular trajectory.

Mobile dunes, blowing sands, and desertification, I suggest, are sites and material forms where we can trace emergent alignments of politics to the inorganic afterlives of the broken land. Recent work in and around anthropology (Kawa 2016; Moore 2016; Whitington 2016; Ghosh 2016; Haraway 2016), including reflections on “an Anthropocene yet unseen” (Howe and Pandian 2016), have aimed to generate a vocabulary for our environmental contemporary and its possible futures. Here, I ask how a politechnics (Anand 2011) of sand control might also generate an archive of resources to stoke speculative futures that fully attend to practical encounters of politics, knowledge, and materials.

Instead of rendering environmental futures through epochal claims and planetary stages, I ask how, in practice, specific environmental processes and materials can provide a repertoire for chronopolitical experiments. As Ann Anagnost (1997, 7) has argued, modern Chinese politics must be tracked through "tactical plays on time," where state practice does not merely have temporal dimensions but is indeed explicitly conceived and practiced as action on time, a catching-up to History. In combating sand, state scientists and engineers do not simply articulate 
environmental futures that are more textured than ecological doomsday narratives with their perplexing universality. They also organize programs of state landscape engineering whose temporal horizons and chronopolitical techniques rework the futurism of the Chinese Communist Party's (CCP) political imaginary. I consider how, in the process of attempting to address specific environmental materialities, antidesertification programs in China enact sand as a substrate for a variegated repertoire of temporal forms and the experimental political forms that attempt to control them - some, but not all of which render the contemporary environment through the figure of coming collapse. ${ }^{3}$ How does sand, rapt in multiple earthy, geomechanical processes, displace the open, linear futures of political time into other chronopolitical forms? If sand encroaches into space, how, too, can it encroach on time?

\section{HOLDING PATTERNS}

Anthropological thinkers have long had an interest in the nature of time in different social orders. Reflections on statist time in recent anthropology trace specific modes of temporal experience as the ongoing conditions and achievements of political practices, running the gamut from "etatized" (Verdery 1996, 40; see also O’Neill 2014) temporalities of waiting and boredom to the repetitive cycles of failure and deferral in technocratic programs of governance (Ferguson 1994). Such writing extends much longer anthropological insights in the mutual interaction of political, environmental, and ritual formations of lived time (EvansPritchard 1940; Leach 1961; Munn 1992). Whereas earlier works in ecological anthropology focused on the self-regulation of human-environmental systems (Rappaport 1968), in contemporary environmental anthropology, scholars chart modes of anticipation that complicate notions of timeless nature, from the idioms of endangerment and extinction that condition anticipatory nostalgia (Choy 2011; West 2006, 1-4) to the various modes of natural history that firmly situate nature in time (Raffles 2002; R. White 1995). Together, these varied works signal an orientation toward specific modes of experience in time-historical, political, natural - that emerge through potent nexuses, not all of which can be attributed to human agents.

Exploring how, in the encounters that drive state environmental construction in China, engineers and scientists reorient their temporal horizons through forms of geophysical and ecological future-telling demands that they grapple with environmental processes, grasped through scientific and practical training but not reducible to these ways of knowing. Geophysical and ecological temporalities 
traced through sand complicate the state-generated and personal futures that have long been a mainstay in Chinese politics. The future-orientation of modern Chinese politics and, more broadly, a contemporary investment in speculative, anticipatory things (Adams, Murphy, and Clarke 2009) have long made the future a tactical achievement of governing. Lisa Rofel (1999, 9-10) writes that the "repeatedly deferred enactment marked by discrepant desires that continually replace one another" has closely tied together state programs of modernization with continually frustrated anticipation in time. In Reform China, the loosening of state monopolies on future-making (Buck-Morss 2000) has given rise to new possibilities of desirous consumer futures amid the Chinese amalgam of authoritarian control and market experiment (Ong and Zhang 2008; Rofel 2007).

"Traces of the future" orient the present as "a placeholder for things to come" (Braester 2016, 17), a transitive moment in the realization of utopian promises. In the People's Republic of China, there has been a succession of official futures, from Mao's worker's paradise to the new promises of consumer paradise (Li Zhang 2010) in infinite economic development. While for state theorists, the environmental problem suggests passage into the next historical, ostensibly ecological stage of Chinese socialism, desertification politics takes shape as a site for the proliferation of environmental-material temporalities that undercut any sense of statist politics unfurling in a singular form. A keen sensitivity to environmental processes reshapes the chronopolitical stakes as political and material accounts of the future pattern into one another.

Scientific and engineering engagements with a material as commonplace as sand can serve as a test case for forms of political time under the apparent encroachment of environmental forces. Sand is not a single thing (Mol 2002). The various technoscientific and engineering agencies that seek to control it attune to its multiple properties (N. Shapiro 2015) to develop an arsenal of chronopolitical interventions. As it flows in dry waves or sustains successive plant communities, it appears as a material in and at the cusps of multiple processes, as well as at the center of political and technoscientific experiments.

In projects of geophysical stabilization, sand's times confront the unity of the promissory futures of the Chinese state's modernization program and the historical emergence of a future populated by processes that can be traced through and projected out of the Chinese earth. To think with Reinhart Koselleck (2004, 2), "what follows will therefore seek to speak, not of one historical time, but rather of many forms of time superimposed one upon the other," with a particular attention to how forms in the mobile sand pattern into the temporal grounds and 
horizons of state action. For state bureaucrats, ecologists, and sand-control engineers, the earth appears as a mobile quantity, the material substrate of many futures in a tangle of engineering techniques, ecological interventions, and anxious hopes for topographical control and the revivification of a sand-choked future. ${ }^{4}$

To attend to sand, for the scientists, bureaucrats, and engineers, is less to tell a history than it is to frame a metahistory. Metahistory is a term I borrow, of course, from Hayden White (1973), who used it to investigate forms of emplotment in historiographic writing. Metahistoric genres and forms generate narrative expectations and futures in a story; these forms are out of time, but they structure time, including the chronotopes of ethnographic writing (Fabian 1983). As David Scott $(2004,19)$ argues, specific generic forms hold any particular political present in relation to "the salience of the horizon in relation to which it is constructed." Whereas White and Scott explore metahistoric genres as powerful literary conventions, for scientists and engineers contending with sand's slippery mobilities, material processes organize their own countervailing modes of time with which state programs must grapple.

In an extension of White's and Scott's literary methods, sands, deserts, and dunes can be productively explored as forms, in Eduardo Kohn's (2013) sense. These forms undergird ways of emplotting futures in consequential ways, ones not limited to the literary and generic conventions structuring historiographic narratives. Form, writes Kohn (2013, 180, 183), manifests in "self-reinforcing pattern[s]" that propagate across domains. In this propagation, politics and temporalities are "mediated and mutated by a form that is not exactly reducible to human events or landscapes," even as they shape them. Sand substantiates various temporal forms that powerfully interact with given political temporalities.

\section{WAITING FOR THE HORIZON}

From a pavilion atop the reservoir that feeds Minqin County, the county's main town appears as an island between two arid areas. Lodged between deserts, Minqin is acutely vulnerable to engulfment by sand pressing against the main town on both sides. The declaration of the county as a key zone in the nation's fight against deserts has drawn resources in the billions of renminbi, expertise, and political attention to this unlikely place, which is already 95 percent covered in sand. This sandy vista is the first that greets any visitor to Minqin as he or she emerges from the sheltering colonnade of windbreaks protecting the only road into the county. In the absence of local surface water, this reservoir holds and drains the diverted Shiyang River. Its waters feed the antisand forestry programs 
that have sprung up around the town like medieval fortifications, a moat between city and sand.

Keeping Minqin unburied is a key symbolic achievement in the state's campaign against sand. The continuing existence of the city marks a key policy goal of high-importance central government programs like Project 937, which has supported sand engineering to hold the deserts at bay while simultaneously implementing a state-supported depopulation of the oasis. As sand threatens the very possibility of ongoing habitation, Minqin has become an exemplary landscape. Its predicament thus contains and doubles a China splintered into places that can be plotted in various stages of burial, affixed to stages in the timelines of sand. Minqin is widely presented as a political and technical proxy of the active deserts that loom just one hundred kilometers outside of Beijing's city limits.

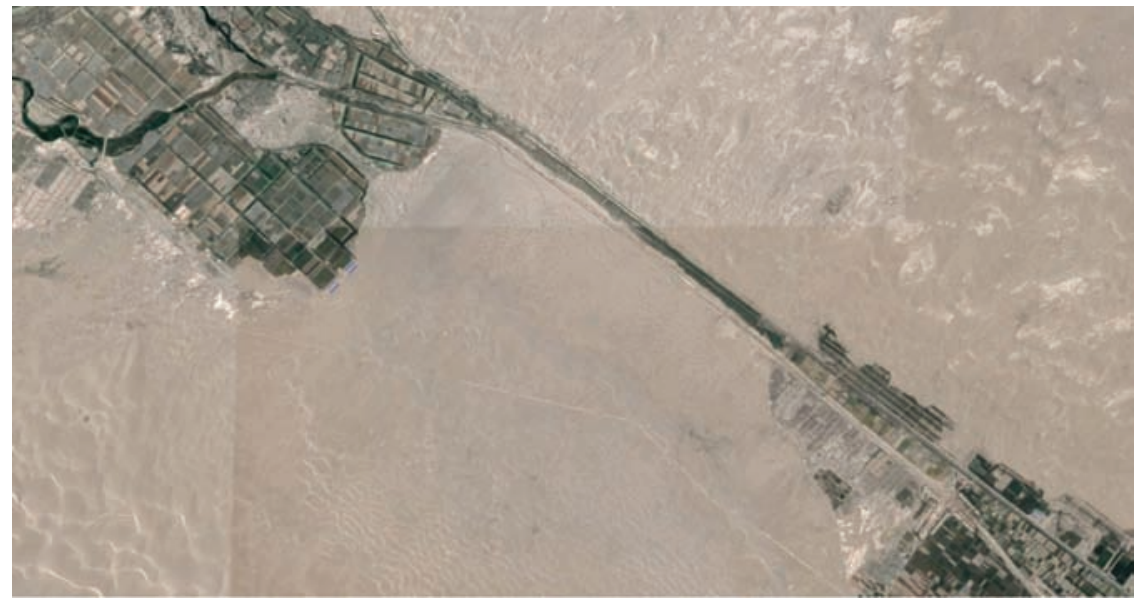

Figure 1. Minqin County's main road. Image by Google and CNES/Astrium, cropped by Micah Hilt.

Central government parlance designates the movement of the sands a "swallowing," claiming that Minqin sits at the "throat" of the deserts. It is a place that can only be said to still exist. Everywhere, the city's predicament is presented in relation to the fearful future moment at which the two deserts touch, rendering it uninhabitable. The looming end drives changes in the social and physical landscape of the region. It has spurred a general reorganization of government in this ex-oasis through the politics of sand control. The massive investments in controlling the desert are conditioned by and elaborate this sense of an ending that is always, literally, on the horizon. 
Minqin's slogan, visible for teams of visiting cadres and forestry workers and often repeated by them as a quick summation of their task, narrates political investment and urgency in reference to a future that must be averted at all costs. Penned in the calligraphic hand of provincial geologist turned premier of the CCP, Wen Jiabao, the slogan demands that "Minqin must not be allowed to become a second Lop Nur." Lop Nur was, like the lakes that once sprawled over Minqin's oasis, for centuries a massive inland sea in the neighboring Xinjiang region. In 1973, it was declared officially dry, leaving a massive alkaline footprint that has become a major source of dust storms in western China.

Wen's Minqin is already located as a point on the timeline of its own disappearance, one that approaches the city in the backward shadow of its coming negation. The slogan enacts a call to a politics that approaches the future as an event to be held at bay. It does so by linking Minqin's future to a past disappearance, and both to the development of deserts in general.

Here, political action addresses a future that hurtles closer by its own progression. In Minqin, a politics against the desert takes the structure of a negative command. The triumphalism of infinite progress so common in state narratives is reshaped through the ongoing work of holding sand against its powerful tendency to spread. Such a politics in sand no longer addresses itself to a utopian future, but merely to the aversion of an ending already in process. Nor is there a sense that the state can do anything better than keep the desert at bay in a tentative stalemate that may at any moment tear open. It is a chronopolitics of stalling. Wen aligns political intervention with preventing an event that has already happened and, left to itself, is on the brink of happening again.

I have come to Minqin with a group of forestry officials making their pilgrimage to what has become a mecca in the world of Chinese antidesertification politics. They comprise a group of technocrats, scientists, and bureaucrats charged with holding the desert at bay. Some, like Tian, are local forestry cadres invested in saving their hometown. Others, like Li Ming, my ecologist friend, hail from other places in the institutional geography of state sand control, including Beijing. We leave the promontory at the reservoir's edge and embark on an inspection tour that will take us past half-buried barricades at sand's edge and into the desert, where sand-breaking grids built of straw, nylon sandbags, or green plastic netting designed to function and look like sand-holding vegetation undulate with the ebb and flow of the dunescape.

For the foresters, the landscape is a monument to its own movements and changes in time. Different places become exemplars of stages in the life history 
of desertification. The series of sites string together as moments spread in a tableau over the county's sand drifts. Its progress can be read through the evacuated villages and buried fields that extend far past the sand's edge. It is in the ruttedout trails ballooning off paved roads upon which sand has encroached in smooth pools, pools tracing the shape of the wind. Buried and toppled sand-control infrastructures mark the desert's advancing power.

To the officials, the land is movement; it is speed. Speed here does not connote a quickness, but rather, a relation between time and distance. It does not stop; it only rests. The land's motion and stability do not appear as opposites, but rather as two possible expressions of this time-space of sand. Sand, rendered as material velocity, incites a reflection on speed in counterpoint to the "contraction in time, the disappearance of territorial space” that Paul Virilio (2006, 156) identifies with modern technologies. At the reservoir's ridge, the engineer Liao speaks to the group, framed by the stunning backdrop of a town pressed on both sides by walls of sand. "The sand moves an average of ten meters per year from each side, sometimes reaching twenty meters," he estimates. He presses his hands together to simulate the movement of the two deserts. "When the two deserts hold hands," he says, "not only will Minqin disappear but this whole region will have changed, in just decades, from a lush oasis to an unbroken plain of sand." Where geological epochs arrange vertically in stratigraphic layers, Liao marks and projects the passage of time moving horizontally as an advancing contour on the earth's surface.

Forestry and sand-holding programs are techniques for breaking this rate by modulating sand's speed. The literary scholar Rob Nixon (2011) suggests that environmental processes like desertification fail to become properly political because such "slow violences" fail to breach the threshold of attention in a politics oriented toward spectacular events. Speed, Nixon suggests, is a condition of politics as such, and more importantly, there is a temporal disjuncture between the slowness of environmental catastrophe and the short attention spans of contemporary politics. Speed is thus a threshold for the attentions that can be called properly political. Liao and the foresters, invited to imagine Minqin's future as a process of inexorable burial, articulate the desert's speed as both fast and slow. When terra firma can shift into a mobile substance (Choy and Zee 2015), any movement is too fast. And yet, because Minqin's burial may still take decades, the problem of desertification is one that remains forever in a future at once too close and too far. 
Such a process and politics elude the binary of fast politics and slow environment implied by the term slow violence, with its simple mismatch of environmental and political speeds. Indeed, Minqin, whose end is both imminent and yet still always in the future, remains caught in a period of waiting, wherein the end is always present and still not immediate. Joseph Masco (2008, 361-62) explores the depiction of nuclear holocaust in early Cold War America to argue that the "national contemplation of ruins . . . created a new citizen-state relationship mediated by nuclear fear." The constant depiction of future ruins was a technique for the conditioning of an unsettled everyday affect, a sense of living emergency. In Minqin, of the many ways in which political practice and lived time are oriented toward a coming disaster that is both too fast and too slow, the present has become an intermediary period. While Masco reads the urgency of nuclear threat as animating a sort of frenzy, one that persists in contemporary American antiterror campaigns, in Minqin, the urgency is of a different kind: that of waiting. This waiting must be prolonged. For the forestry officials, Minqin only still exists. Preventing Minqin from becoming a second Lop Nur, or a cautionary vision of a future Beijing, means that sand-control efforts locate the present in the fearful anticipation of desert encroachment. They are looking for a holding pattern, attempting to forestall the future by engineering the landscape into a stasis carved against the progression of sand.

The remaking of Minqin's social and physical landscape therefore is a means of engineering space to engineer time. Sand-control infrastructures that stall the flow of the land form part of a more general calculative logic that aims not to obliterate the desert as such, but, for the moment, to stall it in a holding pattern actively poised against sand's futures. A slowed landscape equals a future deferred. Minqin has become a showcase for the antidesertification engineering techniques that, under the implementation of the forestry bureau, have sought to protect the city by a set of practices of zhisha, sand control, or more colloquially, yasha, pressing sand. Around Minqin, there is an engineered landscape at and beyond the sand's edge, 330 kilometers of barriers positioned to cut sharp edges back into a dry, liquid landscape. Further in, there are rolling dunes engineered into tentative stability, part of a spectacular infrastructuralized landscape that stages the encounter between sand and state.

At Laohukou, where the Tiger's Mouth mountain pass funnels air currents into sand-blasting jet streams, Liao, a veteran sand engineer, wends his truck off the road into the curves between dunes, where construction is in progress. Bales of straw collected after the corn harvest in other parts of the region pile high 
onto the beds of trucks. A corps of men, mostly ex-farmers who now work the dunes that have buried their fields, dig the straw stalks into the ground, tracing out an undulating grid of low windbreaks. These grids are one of a number of techniques that environmental engineers employ to slow sand drift by breaking the wind at the dune's surface. These and other techniques recall historical landscape-engineering techniques in China, for instance in the management of the nearby Yellow River (Ling Zhang 2016). Here, they are used across the landscape, rather than in a tight line that hugs the edges of structures. Such physical barriers are replicated in a variety of materials, ranging from other kinds of farm waste to burlap or nylon fashioned into sandbags or low walls. So-called biological methods, like tree-planting or aerial seeding, are prohibitive this far into the desert because of the low water content and the general shiftiness of the soil substrate. In emergency situations, chemical methods, mostly involving the spraying of petrochemicals directly onto the sand, laminate loose sand into a self-adhesive sheet. They turn the dunes into a rolling barrier against themselves, and as time goes on, sand forms into slopes on the inside edges of the squares, rather than moving across the land.

Forestry Engineer Xu, who works for Minqin's county forestry bureau, coordinates the logistics of rounding up materials and labor for construction. He laments the ephemerality of the infrastructure that today proudly announces itself with a slogan written in cornstalks: Fix Sand and Block Wind! Protect our Home! "Grass is organic," he explains, "and so it rots and is subject to erosion. If it is an especially dry few years, the squares may last for four years, but they may disappear as quickly as two." Nylon is more durable, but also more expensive. And even if the grass or nylon squares can outlast the process of their own decay, he explains, it is likely that they will be buried before that time comes.

$\mathrm{Xu}$ also coordinates new construction and planting, which moves one step ahead of the sand's leading edge to slow the dusty flood. "We will be doing this for years," he confides, looking over the organic and abiotic sand breaks that have made the landscape an unnatural infrastructure (see Carse 2012). Construction implies the work of ongoing repair and maintenance, as well as of rebuilding on the buried ruins of earlier projects. The work is labor intensive and sand control has become a major driver of the economy, "catching" those no longer able to work their fields. Closer to the city, the quick-growing poplars and shrubs planted to break the sand demand continuous replanting and watering, but they have a notoriously low survival rate-as low as 30 percent nationally. 


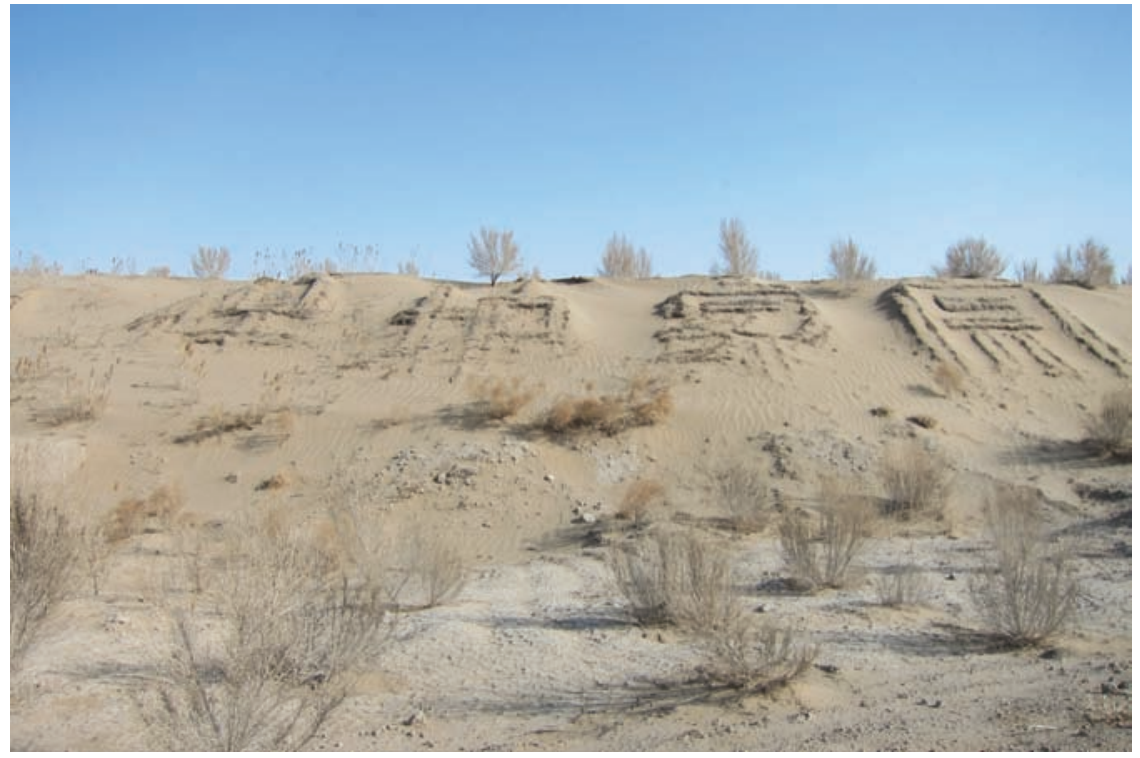

Figure 2. Eroded straw grids exhort, "Protect our home.” Photo by Jerry Zee.

Holding the present in place requires continuous work, a Sisyphean expenditure of materials and labor for an infrastructure that only ever becomes evident when it breaks down or needs repair (Larkin 2008, 235-36). It takes more and more to make sure nothing happens. Facing a coming burial, a politics of sand control demands an apparatus against time. It is a work of containment of the desert future in time and space that will align the "socialist ecological civilization" (Pan 2007) that Chinese state theorists demand with something other than the progressivist emplotment of a "war against nature" (J. Shapiro 2001) so characteristic of the ideological pretentions of earlier state socialism.

Sand displaces that future into an ongoing now, with a politics that aims to continually maintain an unchanging present. It patterns an environmental-political endurance that neither knows nor expects release. It no longer demands any transcendent future, but only the simple continuation of existence. This is a politics animated through the urgency of keeping time and space in a condition of still-waiting, fiercely remaining in the "ontic condition" (Gupta 2015) of a suspension that must not admit a final transition. Still on the horizon, the future is the space of a holding pattern that, if possible, can persist a few more years. 


\section{SUCCESSIONS}

It is after dinner, but the sun has barely begun to set in the big, high summer sky. Naiman's desertification research station in eastern Inner Mongolia, one of a dozen scattered around China's desertification hot zones, buzzes into life as people settle in for evening activities. Summer field research feels like summer camp for the teams of ecologists, geographic information systems (GIS) experts, hydrologists, dune scientists, and engineers.

Li Ming, my ecologist friend who will take me to Minqin months from now, and Little Tu, a first-year ecology PhD student, suggest that we walk the grounds behind the institute. Little Tu, who is doing field research in Naiman for the first time, has the unenviable task of processing sand samples through a sieve with the back of a spoon for later experimentation. Students and young professors like these conduct the bulk of the research at the station. As dusk approaches, they want to climb the watchtower, where we can watch the sunset while eating apricots from the tree near their dormitory. The paths on the institute's grounds curve and meander through what Li Ming says were sand dunes just years earlier. Now, they are dense and unruly with branching shrubs, stands of small trees, and low, weedy grasses that spill over the footpaths. Climbing the watchtower, Little $\mathrm{Tu}$ muses that one day, before summer ends, they could light fireworks off the watchtower's platform.

Looking back over the half-dozen main buildings of the field station, then turning to face the horizon, Little $\mathrm{Tu}$ notices that the vegetation changes in thickness and density. She discerns a botanical gradient, from trees to shrubs to grasses, blotching into patches on the sand before thinning into bare, yellow dunes. Li Ming, the senior of the two desert ecologists who is just starting his first position as a full-fledged state ecologist for the Chinese Academy of Sciences, listens to her. He left his hometown in China's subtropical south with a romantic longing for the open landscapes of northern China's steppes, and now, deserts. As she speaks, interpreting the patches of plants (cf. Tsing 2015) in the late summer dunes, he interjects here and there to identify key grasses, shrubs, and trees, first in Chinese and then in Latin: shami, yanhao, shaliu; Agriophyllum squarrosum, Artemisia halodendron, Salix cheilophila.

It is not my first time wandering on the grounds with researchers at the station, for whom the changing communities of plants serve as a living example of the powers of desert ecology to root dunes in place. Little Tu knows that the species Li Ming names occur naturally on dunes in the region; she also knows that some of these plants, like the dwarf sand willows rooted closest to the 
station's buildings, are strategic species for dune stabilization projects. Plant growth is a stabilization technique. Little Tu wonders aloud, "How many different kinds of plants does it take to fix a dune?"

"The number of species is not the important factor," Li Ming replies, shifting subtly into a pedagogical mode, and now addressing both of us. "From here, we can see several species, all at once, so it looks like a single community of plants. But look, the species are not evenly distributed - there are trees there, but not at the sand's edge." Tracing his finger across the land, from the open dunes through the gradient of plant species, he invites us to see the subtle progression in plant communities as various discrete moments, plotting out sequential years.

Li Ming exhorts us to see the diverse communities as consecutive slices of time, a simultaneous diachrony across the dunes, with its beginnings on the open drifts and its endings in the stands of sand willows. He continues, "When we come back next summer, the way that the plants are distributed will be different again: trees will replace some of the shrubs, and shrubs will replace some of the grasses. The shami grasses will be denser, and there will be new shami in the sand. The ecology is more unstable and more fragile where there are bushes instead of trees, grass instead of shrubs, and sand instead of grass. It is still developing, and where there are trees, it is more stable. We are not interested in the number of species, exactly, but in the stability of the ecosystem." The graduated composition of species on the dunes is a way of emplotting dunes into a process of vegetation change.

This process is a version of the classical formulation of ecological succession, first pioneered in Henry Chandler Cowles's (1899) studies of vegetation on the dunes at the shores of Lake Michigan, and then in Frederic Clements's (1916) paradigm, with its organismic underpinnings. Ecological succession charts a process in which dunes can be imagined as passing through successive botanical stages. According to the story of succession, on a denuded landscape, pioneer species establish and create the conditions for others. They are subsequently replaced by successor species that, in turn, create the conditions for their own overtaking and replacement by new species. Each stage stages the next, so that weedy pioneer communities are already inhabited by the promise of stable climax communities. ${ }^{5}$

Ecological succession is a way of seeing sand at the intersection of multiple environmental processes, some of which can be mobilized against others. It is both a way of telling time on dunes and of giving form to potential action into that time. Research in Naiman is an interdisciplinary enterprise, oriented toward developing dune-stabilization techniques. Its original incarnation, in the 1960s, was as an environmental engineering institute, coordinating sand-control projects 
alongside the desert-crossing Tongliao-Beijing railway at a time when sand encroachment caused up to fifty derailments a year throughout the country (Wang and Zhao 2005). Principles of ecological succession allow state ecologists to see bare dunes as future forests, and to pose the mobility of bare dunes as the starting point of an ecological process that will culminate in stabilization. At the desertification research station, ecology is both a science for understanding the dunes as shifting arrangements of biotic and abiotic things and a tactical element in the enterprise of dune stabilization. Ecology toggles between scientific practice and engineering technique. This doubling of ecological time is a research objective.

For scientists at the station, the ecological stabilization that Li Ming describes is fungible with the stabilizations demanded by sand-control programs. Further into the process of succession and the arrival of a stabilized ecosystem, plants tend to establish more densely and the sand-securing capacities of deeper and more robust roots increase. Indeed, on the dune-surveying trips that groups of students and scientists make each day, documenting plant species and estimating vegetation cover on a square meter of surface sand are ways of locating a dune on the quadripartite scale of dune mobility. The character of the vegetation on a dune's surface helps scientists determine whether a dune is mobile, semi-mobile, semifixed, or fixed. Ecological and geophysical stabilization appear as faces of the same sand-engineering process, and succession describes both an ecological process and a potential geoengineering technique. On moving dunes, then, ecological succession opens ways of mining the sand for its biotic potential to unearth futures that oppose the unending advance of dunes across a landscape. As a competitive mode of sand-time, it allows dunes to exist perpetually at a crossing point between two sand-timelines: the mobility of encroaching dunes contends with ecological succession, wherein sand becomes self-stabilizing botanical substrate.

In ecological succession a bare dune marks a starting point for a new process whose futures are already contained in the first weeds on a dune's slope. Xia, a teacher and an ecologist a few years older than Li Ming, insists that dunes are sites of ecological potential. She sinks a shovel and digs a hole less than a meter into the side of a dune to expose damp sand. "Look: sand is excellent for holding water and preventing desertification. These dunes can support robust plant life," she insists, pointing to the dunescape as a massive reservoir for botanical stabilization. Xia's desert is, following Elizabeth Povinelli (2015, 170), a "space where life was, is not now, or could provide the conditions for life." A water-sealing dune, Xia explains, is a potential habitat for sand-engineering plants, and for a scientific forestry that adheres to and mimics the principles of ecological succession. 
A restless dune marks a point of eco-geophysical intervention. It shifts from the result of desertification to a cusp between two modes of environmental time. At this cusp, the future is a site of technical intervention where "the sense of the present as ruined time" (Scott 2014, 12) is also the precondition for sand ecology to begin rooting stability back into the land. Dune sands appear as both an aftermath of degradation and a growth medium for tenacious, infrastructuralizing species. Ecological sciences assemble into a political toolkit that collects engineering techniques as tactical means of emplotting and realizing other futures. They aim to forcefully derail sand-time from one track to another, one where the desert is a future and not a future burial. It is a means of effecting a kind of temporal capture, whereby the beginning of the succession process already gestures at its completion.

It should come as no surprise, then, that although the stability of an ecological community is a goal, the scientists generally focus on the beginnings of the stabilization process. It is the pioneer species and not the climax community that student scientists are trained to notice. On an early-morning dune-surveying trip, a recent $\mathrm{PhD}$ and specialist in remote sensing, Liu Jun, leads a van full of students several dunes deep into Naiman's Ke' erqin Sandy Lands. We follow him in a loose cluster into the depressions between the high slopes of dunes until he signals us to stop. He reaches down to pull up a tiny green sprig of a leaf, about the size of a clover. It pulls easily out of the loose sand, and several grains of sand hang delicately on its tender root.

"This is shami," he says, speaking of a hardy grass adapted to dry and unstructured sand. Looking around, I notice a sparse carpet of shami on many parts of the dune. I am not the only one who has not taken note of it until now. "Shami grows quickly, and it is one of a few plants that thrives on mobile dunes," Liu Jun says. "It may look like nothing, but shami is centrally important in allowing other plants to establish.” Pioneer species like shami are crucial not only because they are proof of ecological process but also because they change soil conditions in ways that allow other plants to establish. In the sparse leaves and blades, it is possible to envision - with some imagination — shrubs and trees to come on the surface of a stabilized dune.

Pioneer species, therefore, kick-start ecological time, promoting subsequent waves of colonization. They matter especially because they indicate the renewal of an ecological time already occupied by its projected realization. Many ecologists 
at the station study pioneer species. Li Ming and a team of ecologists are especially interested in studying a shrub, yanhao, to understand how it prepares sand as a habitat for larger flora. Yanhao can continue to grow on fixed dunes, therefore limning stages of succession. A study published in 2014 and based on research at Naiman argues that yanhao, "under nutrient limitation [in shifting dunes] is more likely to manage with a low level of nutrients in senescing leaves, giving this species an advantage in infertile soil" (Li et al. 2014, 182-83). In particular, the study suggests that in nutrient-poor environments, the shrub incompletely reabsorbs foliar nutrients, which means that that the plant and its falling leaves contribute "to the return of high-quality litter to the soil." This starts a multiplier effect by which decomposing plant matter "accelerates leaf litter decomposition and nutrient mineralization." In their conclusions, the study's authors suggest that yanhao accelerates the process of dune restoration. The plant itself here appears as both an indicator and an accelerator of ecological time on the dune, as it speeds the process of succession by stimulating the improvement of the dune's nutrient environment for other plants. The manipulation and acceleration of successive communities of plants appear as part of a potential armory of sand-binding interventions, an engineering technique alongside and in tandem with infrastructures like grids. Indeed, ecologists discuss the straw and nylon grids as ways of engineering habitats for sand-pioneering species by creating tiny wind shelters where shrubs and grasses can root more easily.

The ecologists at Naiman believe that if dunes could be left alone and pioneer species would be allowed to establish themselves, then ecology would take its course. Where much of contemporary ecology outside of China has shifted from the orderliness of succession to chaos ecologies (Worster 1990), these scientists see the dunes as sites of a latent ecology just about to burst back into life. For them, ecological time propagates into a politics wherein succession is the template of an ongoing reactivation of time; its stagelike progressivism formally echoes that of Chinese socialism's theory of itself. ${ }^{6}$ As we sit on the institute's watchtower, we face the sunset, looking at where the open dunescape breaks into a patchwork of grasses and pioneer shrubs. Little Tu leans back, as if to linger for a moment in the quiet calm of a future always starting anew.

\section{CODA: Five Thousand Years}

It is often said that China has had a continuous history of five thousand years. At times, the cliché expresses a pervasive cultural chauvinism through the profundity of civilizational time. At others, it is a way of neutralizing the tumultuous 
recent past into the gravity of deep historical time. Those involved in antidesertification work often presented it to me as a subtle reminder that it is possible to describe environmental and human time on the same scale and in the same time frame. Five thousand years admits no necessary distinction or sense of a mismatch in speeds and scales, no singular collision of nature and culture.

I heard the phrase very often from scientists when driving with them through Naiman and its alternating patchwork of pastures, newly opened farmlands, semidegraded fields, and rolling dunes. They deployed it, in particular, when I expressed surprise over how calm they seemed over the emergency of desertification. Five thousand years offered a trope through which they could explain to an outsider the ordinariness of this apparent disaster, subsuming its exceptionality into an account of ordinary environmental processes.

Tingting, a young hydrologist at Naiman station, for instance, thinks of the depth of time not in relation to permanence but rather as a reminder of the very transience of the present as a moment in a longer cycle. As our van speeds past the new furrows of a freshly plowed piece of farmland, ${ }^{7}$ she chides me for imagining that this opening signals a violence against pristine nature:

All over China, places like this . . . have been settled for thousands of years, and the land is put to many uses and undergoes many changes. It is not like in America or elsewhere where land is plentiful: here, there have always been people and they have always worked the land in different ways. When we see these farmlands being opened up, this is something that has happened many times in the past. People farmed the land, and that changed the land and it deteriorates and underwent desertification. When desertification has happened in the past, grass has come back, and then people will come in and graze [their animals] here, and then, when the land is ready, others will come in and farm again. This has happened many times over thousands of years here.

Tingting is not elaborating a specific catalog of events, but rather the environmental form through which a temporality and process of environmental change can be imagined. The various kinds of landscape — dunes, pastures, fallow - rearrange as points in a process that extends backward and forward in time. Her account of the earth as a long cycle of rising and falling social, economic, and ecological regimes recalls the models of ecological disturbance and succession through which the scientists see a dynamic earth, as well as the long cyclical returns of Chinese dynastic time (Levenson 1968). The opening of new farmland, 
a primary driver of desertification, is for her a reopening, an indelible moment in a cycle that has lasted since time immemorial. It is proof of the perpetuity of the land as itself a process of change, one that is driven neither by human agency nor by the workings of an extrahuman nature. Just as state ecologists comb bare dunes for signs of renewed succession, the telescoping of the variegated landscape into a tableau of a millennia-long social-economic-ecological cycle makes apparent endings the necessary grounds for new beginnings. For Tingting, the disturbance is already implied as part of the ongoing operation of the cycle, just as its eventual rehabilitation is; it is the normal disaster.

At the center of her way of seeing the earth, where succession has shifted from an ecological principle to a framework for general time, is a relentless, cycling change that binds together the endurance of China and the endurance of the earth. Tingting's earth is not an object but a process, gathering and bearing the effects of economic, ecological, and geophysical processes. China and its difficult land urge a thinking with perpetual cycles that repeat with all the spontaneity and mystery of the changing seasons or the rise and fall of governments. In this long China, the earth is the substrate of its own time. Tingting offers an account of a landscape that has long been embroiled in human practices and yet cannot be called anthropogenic - if the term indicates human life as an excess over environments rather than a moment in them. In Tingting's earthly process, there is no need to understand the environmental present or future as a rupture in time, nor to ask for five thousand years to bear themselves as a history of trespasses. ${ }^{8}$ Her landscape is an earthly history of endurances, where the earth, as this knot of processes, is the engine and measure of itself.

Apparent end points become the proof of a cycle beginning again. The depth of time, where boundaries blur between the perpetuity of the state and the perpetuity of the land, offers a way of emplotting the environment as an entanglement of physical, demographic, economic, and climatic processes, without any need to pinpoint a moment in which one engulfs the other. What sand and the politics of its containment may offer are a gesture toward a different kind of politics in time: a politics formed through the earth and its many rhythms and materials. That is to say, the materials and processes that give shape to the earth and its changes elicit and pattern political possibilities; they may evince political futures and tactics for shaping them.

As those most invested in sand control seek to contain it, temporalities of sand figure in diverse formations. In this way, sand shifts subtly from an environmental problem open to pacification by technopolitical intervention to a key actant 
in shaping the governmental interventions meant to finally control it (Callon 1986). In many modes of encounter, more-than-human landscapes scaffold emplotments of political and environmental futurity that relay through more-thanhuman becomings. Sand becomes the material condition of a metahistorical form that emerges in complex physical, political, and ecological intra-action, even as it shapes new forms of political time.

The horizons of politics, in the worlds of sand control, take their shape through the horizons of the expanding deserts. The announcement of the Anthropocene must be taken as a challenge to unearth ways of imagining futures in more-than-human worlds, beyond the timelessness of Nature and the imminent endings of disaster environmentalisms. Vibrant, potent, and irreducible to human design (see Bennett 2010), environmental materialities and processes displace and force open an anthropocentric temporal imagination. At the shores of the desert, we may yet discern in the sand ways of living at the end of the world, enduring its erosions or opening the future anew.

\section{ABSTRACT}

This article considers possibilities for posing the relationship between historical, political, and environmental time - a key provocation of what has been called the Anthropocene-by exploring how sand gives form to political time in Chinese state antidesertification and sand-control efforts. Through an ethnographic exploration of how scientists, engineers, and bureaucrats in two desertification emergency zones in northern China read landscapes through sand as a substance embroiled in multiple physical, geological, and ecological processes, this essay argues that sand emerges as a form not simply for apprehending alternative ways of accounting for and narrating the passage and texture of passing time but also for giving shape to the futures with which environmental politics in China must contend. It also constitutes a set of tactical techniques for intervening in and shaping environmental processes. As sand gives form to multiple chronological forms, it further reworks the chronopolitics of the grand futures of state-sponsored economic development into what I call "holding patterns," techniques of environmental management shaped by earthly temporalities and aimed at holding the unruly time-spaces of moving sand in place. Sand's motion and stabilization become the physical substrate for new modes of political fortune-telling, sometimes spelling out endings in the anticipatory spectacle of buried cities, but sometimes also providing the architecture for regenerative ecological futures. [China; environment; sand; temporality; futurity; Anthropocene]

\section{NOTES}

Acknowledgments First and foremost, thanks to my friends in China's antidesertification programs and the Chinese Academies of Sciences and Social Sciences, without whom this work 
would not have been possible. Many thanks to Aihwa Ong and Gabriel Coren, who read earlier drafts of this article, and to Alex Blanchette, Sarah Vaughn, Nick Shapiro, and Bridget Guarasci, who read and debated it in revisions. In its multiple iterations, this article has benefited from the kind and joyful attention of many more than I can list. These include Hoon Song, Jia-Ching Chen, Emily Ng, Vivian Choi, Candis Callison, Derick Fay, and the Department of Anthropology at the University of California, Santa Cruz, especially Andrew Mathews and Lisa Rofel. The Program in Science and Technology Studies at the University of California, Davis has been the most caring and supportive place to write and learn. The encouragement and insight of four anonymous reviewers, Dominic Boyer, James Faubion, and especially Cymene Howe have improved this article at the every level; they are the substrate through which it has taken form. Most of all, thanks to Tim Choy, for everything. Research and writing were made possible by the Wenner-Gren Foundation, the University of California Pacific Rim Research Program, the University of California, Berkeley Center for Chinese Studies, and the Mellon Foundation/American Council of Learned Societies.

1. China's semi-arid interior has for decades suffered massive desertification and has recently drawn scientific and journalistic attention for its epidemic of lake disappearances (Huo 2011).

2. China's antisand programs unfurl in a number of overlapping geographies, from the various airstreams that make deserts into dust-storm source areas for downwind places to the sprawling geography of field stations in key demonstration zones (Zee 2015). Sand and wind, as the constituents of a dust storm, have not only reshaped the temporal horizons of political intervention but have alos laid the environmental architecture for new administrative zonings (see Ong 2006) across and beyond northern China.

3. I understand this work to be fundamentally consonant with the collaborative alterspeculations of the uncertain commons $(2013,10)$ writing collective. "To divine," they write, "is to dream the future - namely, to live the present in the tense of the future anterior."

4. It should be clear that this attention to the interaction of temporal forms across nonhuman and human registers is not bound to a primordialist conception of nature as a sphere outside of human intervention, or the raw material on which culture acts (Strathern 1980). I am indebted to writers who have endeavored to theorize contemporary environmental being as already changed and therefore bearing an ongoing capacity to change, what Michelle Murphy (2015), in a biotic idiom, has called "alterlife."

5. Succession and climax models, as Donald Worster $(1977,1979)$ notes, gained footholds in land-restoration campaigns in the United States during the Dust Bowl period of the 1930s, as New Deal conservation programs aimed to control so-called "black blizzards."

6. A much longer reflection exists through Chinese history on the nature of Chinese political time. Much of modern Chinese state political and philosophical thought has responded to the problem of how "to be modern and Chinese, that combination so desperately sought through a century of reformist and revolutionary exasperation as a seemingly immobile China and an all-too-kinetic West" (Levenson 1968, 78). Stagist and progressivist conceptions of history provided and continue to provide an official historiographic form, not only for making sense of Chinese pasts but also for angling toward futures framed as a succession of state-announced stages.

7. The recent opening of new farmland in northern China, especially on pasture lands, is an effect of major national policy that demands the replacement of farmland lost to urbanization, especially in the densely populated south, to retain a constant amount of total farmland. This follows on large-scale agricultural conversion campaigns during the Cultural Revolution that significantly drove desertification in the utopian goal of "Making Grain the Key Link" by making historically pastoral regions into a bread basket through conversion to farmland.

8. Conversely, Tingting's accounting of landscape change in social-ecological succession leaves little room for an accounting of actual changes in use patterns, especially in the past century. 


\section{REFERENCES}

Adams, Vincanne, Michelle Murphy, and Adele E. Clarke

2009 "Anticipation: Technoscience, Life, Affect, Temporality." Subjectivity 28, no. 1: 246-65. https://doi.org/10.1057/sub.2009.18.

Agard-Jones, Vanessa

2012 "What the Sands Remember." GLQ 18, nos. 2-3: 325-46. https://doi.org/ 10.1215/10642684-1472917.

Anagnost, Ann

1997 National Past-Times: Narrative, Representation, and Power in Modern China. Durham,

Anand, Nikhil

N.C.: Duke University Press.

2011 "Pressure: The PoliTechnics of Water Supply in Mumbai." Cultural Anthropology 26, no. 4: 542-64. https://doi.org/10.1111/j.1548-1360.2011.01111.x.

Benjamin, Walter

1969 Illuminations: Essays and Reflections. Translated by Harry Zohn. New York: Schocken Books. Originally published in 1955.

Bennett, Jane

2010 Vibrant Matter: A Political Ecology of Things. Durham, N.C.: Duke University Press. Braester, Yomi

2016 "Traces of the Future: Beijing's Politics of Emergence." In Ghost Protocol: Development and Displacement in Global China, edited by Carlos Rojas and Ralph

Buck-Morss, Susan

A. Litzinger, 15-35. Durham, N.C.: Duke University Press.

2000 Dreamworld and Catastrophe: The Passing of Mass Utopia in East and West. Cambridge, Mass.: MIT Press.

Callon, Michel

1986 "Some Elements of a Sociology of Translation: Domestication of the Scallops and the Fishermen of St. Brieuc Bay." In Power, Action, and Belief: A New Sociology of Knowledge?, edited by John Law, 196-223. London: Routledge.

Carse, Ashley

2012 "Nature as Infrastructure: Making and Managing the Panama Canal Watershed." Social Studies of Science 42, no. 4: 539-63. https://doi.org/10.1177/ 0306312712440166.

Chakrabarty, Dipesh

2009 “The Climate of History: Four Theses." Critical Inquiry 35, no. 2: 197-222.

Choy, Timothy https://doi.org/10.1086/596640.

2011 Ecologies of Comparison: An Ethnography of Endangerment in Hong Kong. Durham, N.C.: Duke University Press.

Choy, Timothy, and Jerry Zee

2015 “Condition-Suspension." Cultural Anthropology 30, no. 2: 210-23. https:// doi.org/10.14506/ca30.2.04.

Clements, Frederic E.

1916 Plant Succession: An Analysis of the Development of Vegetation. Washington, D.C.: Carnegie Institution of Washington.

Cowles, Henry Chandler

1899 "The Ecological Relations of the Vegetation on the Dunes of Lake Michigan." Botanical Gazette 27, no. 2: 95-117. http://www.jstor.org/stable/2465177.

Evans-Pritchard, E. E.

1940 The Nuer: A Description of the Modes of Life and Political Institutions of a Nilotic People. London: Clarendon Press.

Fabian, Johannes

1983 Time and the Other: How Anthropology Makes Its Object. New York: Columbia University Press. 
Ferguson, James

1994 The Anti-Politics Machine: "Development," Depoliticization, and Bureaucratic Power in Lesotho. Minneapolis: University of Minnesota Press.

Ghosh, Amitav

2016 The Great Derangement: Climate Change and the Unthinkable. Chicago: University of Chicago Press.

Gupta, Akhil

2015 "Suspension." In "The Infrastructure Toolbox," edited by Hannah Appel, Nikhil Anand, and Akhil Gupta, Cultural Anthropology website, September 24. https://

Guyer, Jane I. www.culanth.org/fieldsights/722-suspension.

2007 "Prophecy and the Near Future: Thoughts on Macroeconomic, Evangelical, and Punctuated Time.” American Ethnologist 34, no. 3: 409-421. https://doi.org/ 10.1525/ae.2007.34.3.409.

Haraway, Donna J.

2016 Staying with the Trouble: Making Kin in the Chthulucene. Durham, N.C.: Duke University Press.

Helmreich, Stefan

2011 “Nature/Culture/Seawater." American Anthropologist 113, no. 1: 132-44. https://doi.org/10.1111/j.1548-1433.2010.01311.x.

Howe, Cymene, and Anand Pandian, eds.

2016 "Lexicon for an Anthropocene Yet Unseen." Theorizing the Contemporary, Cultural Anthropology website, January 22. https: / / www.culanth.org/fieldsights/ 803-lexicon-for-an-anthropocene-yet-unseen.

Huo Weiya

2011 “China's Great Disappearing Lake.” China Dialogue, January 21. https:// www. chinadialogue.net/article/show/single/en/4068-China-s-greatdisappearing-lake.

Kawa, Nicholas C.

2016 Amazonia in the Anthropocene: People, Soils, Plants, Forests. Austin: University of Texas Press.

Kohn, Eduardo

2013 How Forests Think: Toward an Anthropology Beyond the Human. Berkeley: University of California Press.

Koselleck, Reinhart

2004 Futures Past: On the Semantics of Historical Time. Translated by Keith Tribe. New York: Columbia University Press. Originally published in 1985.

Larkin, Brian

2008 Signal and Noise: Media, Infrastructure, and Urban Culture in Nigeria. Durham, N.C.:

Leach, Edmund R.

Duke University Press.

1961 Rethinking Anthropology. London: Athlone Press.

Levenson, Joseph R.

1968 Confucian China and its Modern Fate: A Trilogy. Berkeley: University of California Press.

Li, YuLin, Chen Jing, Wei Mao, Duo Cui, XinYuan Wang, and XueYong Zhao

2014 "N and P Resorption in a Pioneer Shrub (Artemisia Halodendron) Inhabiting Severely Desertified Lands of Northern China." Journal of Arid Land 6, no. 2: 174-85. https://doi.org/10.1007/s40333-013-0222-7.

Liu, Jianguo, and Jared Diamond

2005 “China's Environment in a Globalizing World." Nature 435: 1179-86. https:// doi.org/10.1038/4351179a. 
Masco, Joseph

2008 “'Survival is Your Business': Engineering Ruins and Affect in Nuclear America.” Cultural Anthropology 23, no. 2: 361-98. https://doi.org/10.1111/j.15481360.2008.00012.x.

Massumi, Brian

2009 “National Enterprise Emergency: Steps toward an Ecology of Powers." Theory, Culture, and Society 26, no. 6: 153-85. https://doi.org/10.1177/ 0263276409347696.

Mol, Annemarie

2002 The Body Multiple: Ontology in Medical Practice. Durham, N.C.: Duke University Press.

Moore, Amelia

2016 "Anthropocene Anthropology: Reconceptualizing Contemporary Global Change." Journal of the Royal Anthropological Institute 22, no. 1: 27-46. https://

Munn, Nancy D. doi.org/10.1111/1467-9655.12332.

1992 The Fame of Gawa: A Symbolic Study of Value Transformation in a Massim Society. Durham, N.C.: Duke University Press.

Murphy, Michelle

2015 "Alterlife: Futures in the Aftermath of Industrial Chemicals." Paper presented at "Engineered Worlds," Neubauer Collegium for Culture and Society, Chicago, Ill., October 2.

Nixon, Rob

2011 Slow Violence and the Environmentalism of the Poor. Cambridge, Mass.: Harvard University Press.

O’Neill, Bruce

2014 "Cast Aside: Boredom, Downward Mobility, and Homelessness in PostCommunist Bucharest.” Cultural Anthropology 29, no. 1: 8-31. https://doi.org/ 10.14506/ca29.1.03.

Ong, Aihwa

2006 “Zoning Technologies in East Asia." In Neoliberalism as Exception: Mutations in Citizenship and Sovereignty, 97-120. Durham, N.C.: Duke University Press.

Ong, Aihwa, and Li Zhang

2008 "Powers of the Self, Socialism from Afar." In Privatizing China: Socialism from Afar, edited by Li Zhang and Aihwa Ong, 1-19. Ithaca, N.Y.: Cornell University Press.

Oreskes, Naomi, and Erik M. Conway

2014 The Collapse of Western Civilization: A View from the Future. New York: Columbia University Press.

Pan Yue

2007 “Socialist Ecological Civilization [Shehuizhuyi Shengtai Wenming]." http://www. zhb.gov.cn/hjyw/200702/t20070206_100622.htm.

Povinelli, Elizabeth A.

2015 "Transgender Creeks and the Three Figures of Power in Late Liberalism."

Raffles, Hugh differences 26, no. 1: 168-87. https://doi.org/10.1215/10407391-2880645.

2002 In Amazonia: A Natural History. Princeton, N.J.: Princeton University Press.

Rappaport, Roy A.

1968 Pigs for the Ancestors: Ritual in the Ecology of a New Guinea People. New Haven, Conn.: Yale University Press.

Rofel, Lisa

1999 Other Modernities: Gendered Yearnings in China after Socialism. Berkeley: University of California Press.

2007 Desiring China: Experiments in Neoliberalism, Sexuality, and Public Culture. Durham, N.C.: Duke University Press. 
Scott, David

2004 Conscripts of Modernity: The Tragedy of Colonial Enlightenment. Durham, N.C.: Duke University Press.

2014 Omens of Adversity: Tragedy, Time, Memory, Justice. Durham, N.C.: Duke University Press.

Shapiro, Judith

2001 Mao's War Against Nature: Politics and the Environment in Revolutionary China. New York: Cambridge University Press.

Shapiro, Nicholas

2015 "Attuning to the Chemosphere: Domestic Formaldehyde, Bodily Reasoning, and the Chemical Sublime." Cultural Anthropology 30, no. 3: 368-93. https://

Song, Hoon doi.org/10.14506/ca30.3.02.

2012 “Two is Infinite, Gender is Post-Social in Papua New Guinea." Angelaki 17, no. 2: 123-44. https://doi.org/10.1080/0969725x.2012.701053.

Strathern, Marilyn

1980 "No Nature, No Culture: The Hagen Case." In Nature, Culture, and Gender, edited by Carol P. MacCormack and Marilyn Strathern, 174-222. New York: Cambridge University Press.

Sun, Danfeng, Richard Dawson, Hong Li, and Baoguo Li

2005 "Modeling Desertification Change in Minqin County, China." Environmental Monitoring and Assessment 108, no. 1: 169-88. https://doi.org/10.1007/s10661005-4221-9.

Tsing, Anna Lowenhaupt

2015 The Mushroom at the End of the World: On the Possibility of Life in Capitalist Ruins. Princeton, N.J.: Princeton University Press.

uncertain commons

2013 Speculate This! Durham, N.C.: Duke University Press.

Verdery, Katherine

1996 What Was Socialism and What Comes Next? Princeton, N.J.: Princeton University Press.

Virilio, Paul

2006 Speed and Politics. Translated by Mark Polizzotti. Los Angeles: Semiotext(e). Originally published in 1977.

Wang Tao, and Zhao Halin

2005 "Fifty Years of Desert Research in China [Zhongguo Shamohua Kexue de Wushi Nian]." Journal of Desert Research 25, no. 2: 145-65. http://zgsm.westgis.ac.cn/ CN/volumn/volumn_1302.shtml.

West, Paige

2006 Conservation is Our Government Now: The Politics of Ecology in Papua New Guinea. Durham, N.C.: Duke University Press.

White, Hayden

1973 Metahistory: The Historical Imagination in Nineteenth-Century Europe. Baltimore,

White, Richard Md.: Johns Hopkins University Press.

1995 The Organic Machine: The Remaking of the Columbia River. New York: Hill and Wang.

Whitington, Jerome

2016 "What Does Climate Change Demand of Anthropology?" Political and Legal Worster, Donald Anthropology Review 39, no. 1: 7-15. https://doi.org/10.1111/plar.12127.

1977 Nature's Economy: A History of Ecological Ideas. New York: Cambridge University Press.

1979 Dust Bowl: The Southern Plains in the 1930s. New York: Oxford University Press. 
1990 "The Ecology of Order and Chaos." Environmental History Review 14, nos. 1-2: 1-18. https://doi.org/10.2307/3984623.

Zee, Jerry C.

2015 "States of the Wind: A Political Meteorology of Contemporary China." PhD dissertation, University of California, Berkeley.

Zhang, Li

2010 In Search of Paradise: Middle-Class Living in a Chinese Metropolis. Ithaca, N.Y.: Cornell University Press.

Zhang, Ling

2016 The River, the Plain, and the State: An Environmental Drama in Northern Song China, 1048-1128. New York: Cambridge University Press. 